\title{
Uma Defesa Pesada: a Hiperacumulação de Metais e as suas Consequências para o Ecossistema
}

\author{
A Heavy Metal Defence: Metal \\ Hyperaccumulation and its Consequences \\ for Ecosystems. Plants have several strategies \\ to deal with the presence of biotic and \\ abiotic stresses, such as high concentration \\ of heavy metals. One of these strategies is \\ the accumulation of metals in leaves and \\ branches, which helps defend them against \\ herbivores and, at the same time, allows \\ dealing with excess heavy metals in the soil. \\ However, this accumulation can have several \\ consequences, namely the adaptation of \\ herbivores to heavy metals and their use for \\ defence against other predators. Thus, the \\ transfer of metals from soils along the trophic \\ chain can happen very easily through the \\ accumulation of metals in plants, which are \\ then transferred with varying efficiency across \\ different trophic levels of the ecosystem. This \\ accumulation of heavy metals can reach \\ humans in different ways, having several \\ harmful consequences for health.
}

\begin{abstract}
As plantas têm várias estratégias para lidar com a presença de stress biótico e abiótico, como a elevada concentração de metais pesados. Uma dessas estratégias é a acumulação de metais nas folhas e ramos, o que ajuda na defesa contra herbívoros e permite, ao mesmo tempo, lidar com o excesso de metais pesados no solo. No entanto, essa acumulação pode ter várias consequências, nomeadamente a adaptação de herbívoros aos metais pesados e a sua utilização para defesa contra outros predadores. Assim, a transferência de metais dos solos ao longo da cadeia trófica pode acontecer muito facilmente através da acumulação de metais nas plantas, que são depois transferidos com mais ou menos eficiência para os diferentes niveis tróficos do ecossistema. Esta acumulação de metais pesados pode chegar até ao Homem de diversas maneiras, tendo várias consequências nefastas para a saúde.
\end{abstract}

\section{Introdução}

As plantas estão sujeitas a uma elevada pressão seletiva de vários tipos de fatores bióticos e abióticos $[1,2]$. Por um lado, desenvolveram diferentes estratégias para poderem responder aos ataques dos herbívoros $[3,4]$. Por outro lado, como as plantas e os herbívoros evoluíram juntos (isto é, coevoluíram), existe uma espécie de "corrida ao armamento", em que as plantas usam diferentes tipos de defesas e os herbívoros ultrapassam essas defesas, levando as plantas a desenvolver novas defesas, criando um ciclo complexo e potencialmente infinito de respostas $[2,4]$. Em adição à pressão seletiva gerada por herbívoros, as plantas têm também de lidar com fatores ambientais menos favoráveis, como a seca ou a presença de contaminantes no solo. Um dos contaminantes mais comuns dos solos, devido ao aumento de atividades humanas de industrialização, exploração de minas e utilização de fertilizantes e pesticidas, são os metais pesados ${ }^{1}$ [5-7]. Estes metais pesados podem ser tóxicos, mas constituir também uma defesa extra para as plantas [8,9]. Isto pode ter consequências não só para a interação planta-herbívoros, mas também para os ecossistemas. 0 objetivo deste artigo é resumir o conhecimento atual das defesas contra os herbívoros, o como e o porquê de as plantas acumularem metais pesados do solo e analisar algumas das consequências dessa acumulação nos ecossistemas. 


\section{Uma visão geral das defesas das plantas contra os herbívoros}

Uma vez que não se podem deslocar, as plantas não podem evitar os herbívoros e têm de desenvolver outros tipos de defesas para evitar a herbivoria $[3,4,10]$. De uma forma geral, podem classificar-se as plantas como (1) resistentes, diminuindo a capacidade de digestão ou sobrevivência dos herbívoros, ou (2) tolerantes, em que diminuem o impacto da herbivoria na sua capacidade de sobrevivência e/ou reprodução [2]. Como uma mesma planta pode ser predada por tipos diferentes de herbívoros, a maior parte delas possui diferentes tipos de defesas que podem ser utilizadas contra os vários predadores que as atacam. Os exemplos mais conhecidos de defesas das plantas são as defesas mecânicas: a presença de tricomas (estruturas semelhantes a pelos), de espinhos e de folhas mais rijas (ou espessas) que dificultam a ingestão [11-13]. No entanto, uma planta também pode ter defesas químicas, como a produção de toxinas ou compostos que diminuem a digestibilidade dos tecidos [14-17]. Estas defesas podem ser constitutivas (estão sempre presentes) ou induzidas (só são expressas quando as plantas são atacadas) [17].

Quando as plantas são atacadas gera-se uma cascata complexa que envolve a expressão de diferentes genes que vão gerar defesas diretas e indiretas [14-17]. Há vários tipos de compostos que podem ser induzidos diretamente pela herbivoria, como os glucosinatos, o ácido salicílico, o ácido jasmónico ou os inibidores de proteases. Estes, normalmente, reduzem a sobrevivência, a oviposição, a digestão, ou mudam o comportamento alimentar dos herbívoros [17]. As defesas indiretas geralmente envolvem a produção de compostos orgânicos voláteis que podem atrair predadores naturais dos herbívoros, ajudando a eliminar a fonte do ataque $[18,19]$. Estes compostos também podem servir para comunicação com plantas circundantes, induzindo as defesas das plantas mesmo antes delas serem atacadas.

Existem três grandes classes de compostos químicos envolvidos nas defesas químicas das plantas: os alcaloides, os compostos fenólicos e os terpenos. Alguns alcaloides, como a menta ou a quinina, podem provocar alterações no odor ou no gosto da planta de modo a repelir os herbívoros [2,17], enquanto outros levam ao excesso de estimulação (e.g., a cafeína) ou ao aumento de letargia (e.g., a morfina) quando os herbívoros consomem as plantas [2,17]. Os taninos são exemplos de compostos fenólicos que são altamente tóxicos para os insetos porque se ligam às proteínas da saliva e enzimas digestivas causando a sua inativação $[2,17]$. Os monoterpenos, que fazem parte dos óleos essenciais e especiarias, são tóxicos para insetos e protegem a planta de ataques de bactérias ou fungos
$[2,17]$. Apesar destes compostos serem tóxicos para muitos invertebrados, encontram-se frequentemente na nossa comida (como as especiarias ou os taninos no vinho) ou nos perfumes e odores que nos agradam (por exemplo, a alfazema ou a menta). Para além destes compostos orgânicos, as plantas produzem também diversos tipos de proteínas que reduzem a atividade enzimática de bactérias, fungos e herbívoros, bloqueando as zonas catalíticas das enzimas ou alterando a sua conformação $[2,17,20]$. No entanto, devido ao elevado custo de produção, estes tipos de defesas só são induzidos quando as plantas são atacadas.

Para além da produção destes compostos, algumas plantas podem também armazenar elementos no seu organismo para aumentar a sua toxicidade, como é o caso dos metais pesados [8,9]. As plantas que acumulam quantidades elevadas de metais específicos no seu organismo são denominadas plantas hiperacumuladoras. No entanto, a maior parte das plantas hiperacumuladoras não consegue acumular metais de forma equitativa, estando a concentração máxima dependente do tipo de planta e do tipo de metal considerado $[8,9,21]$.

\section{Acumulação de metais como defesa contra a herbivoria}

As altas concentrações de metais pesados no solo representam um grande stress para as plantas [8,9,21], uma vez que o excesso destes elementoss pode inibir a fotossíntese, a respiração, o metabolismo do nitrogénio, o alongamento das células, etc., o que pode levar à perda de biomassa e à morte da planta [22]. Esta contaminação por metais pesados advém, geralmente, do escoamento de produtos tóxicos de fábricas e da urbanização intensiva do terreno, mas também do uso intensivo de pesticidas, herbicidas e fertilizantes [6].

Os metais estão presentes no solo em diferentes quantidades e vários deles, como o cobalto, o cobre, o ferro, o níquel ou o zinco, são necessários para o normal crescimento e metabolismo das plantas (são chamados metais essenciais) $[2,4,10]$. No entanto, metais (ou metaloides) como o arsénio, o cádmio, o mercúrio, o chumbo ou o selénio podem ser altamente prejudiciais para o funcionamento das plantas e são tóxicos mesmo em pequenas quantidades [8,9]. É importante referir que mesmo os metais essenciais são tóxicos para as plantas desde que ultrapassem certas concentrações.

Os efeitos dos metais pesados do solo nas plantas são complexos e dependem de vários fatores, como o pH, a temperatura, a quantidade de água e a oxigenação, e de vários processos químicos (como a absorção pelas raízes, a dissociação, a oxidação, a troca e transporte de iões) [23]. Enquanto alguns destes processos alteram a disponibilidade dos metais no solo, a oxidação pode mudar a valência do metal, 
alterando as suas propriedades [9].

Apesar dos problemas que advêm da toxicidade destes elementos, é muito comum encontrar plantas a viver em solos com elevadas quantidades de metais pesados. 0 mecanismo mais comum através do qual as plantas lidam com o excesso de metais no solo é evitando que estes passem do solo para dentro das raízes; isto faz-se através da exsudação de ácidos orgânicos que depois se ligam aos metais [23] ou da ligaçãa de metais aos grupos aniónicos nas paredes celulares [24]. Os metais que conseguem entrar nas raízes são maioritariamente acumulados em vacúolos, evitando que sejam tóxicos para a planta $[9,25]$. Adicionalmente, as plantas podem lidar com a concentração elevada de metais pesados através da produção de compostos antioxidantes $[25,26]$.

Outro mecanismo pelo qual as plantas podem lidar com a presença de altas concentrações de metal no solo é a hiperacumulação de metais $[8,9,21,27]$. Este mecanismo é muito mais raro, embora tenha evoluído várias vezes ao longo do tempo, sendo de elevada ocorrência em plantas da família das Brassicaceae [27]. As plantas hiperacumuladoras não excluem os metais, em vez disso acumulam-nos nas folhas e nos caules, sendo capazes de acumular metais em concentrações até 100 vezes maiores do que plantas não hiperacumuladoras $[21,27,28]$. No entanto, esta acumulação pode ter custos para a planta, nomeadamente na diminuição da sua biomassa, na quantidade de água presente nos ramos, etc. [29,30]. Existem por isso várias hipóteses que tentam explicar qual a vantagem evolutiva deste comportamento de hiperacumulação $[8,9,21,27]$, nomeadamente: tolerância/exclusão ao metal, resistência à seca, interferência com o crescimento de plantas vizinhas e defesa contra herbívoros [21,27]. A hipótese de tolerância/exclusão sugere que as plantas fazem a hiperacumulação para retirar os metais das raízes, passando-os para os tecidos das folhas (que são mais tolerantes), sendo os metais mais facilmente eliminados do corpo da planta ao perder as folhas [31,32]. A hipótese da interferência com o crescimento das plantas vizinhas sugere que a acumulação de metais nas folhas faz com que o solo por baixo das plantas fique mais rico em metais pesados à medida que estas perdem as suas folhas, tornando o solo pouco habitável a plantas não tolerantes a metais. Estas três hipóteses tiveram, até hoje, pouco ou nenhum suporte experimental [9,21,27,33-35]. A hipótese mais apoiada experimentalmente, até agora, foi a da hiperacumulação de metais como um terceiro tipo de defesa contra herbívoros (defesa elementar) $[8,9,33,35,36]$, que poderia ou não interagir com as defesas constitutivas e induzidas da planta [33].

Existem vários estudos experimentais que suportam a defesa elementar como um possível mecanismo de proteção contra a herbivoria e bactérias ou fungos, podendo explicar a vantagem evolutiva desta estratégia $[8,9,20,21,37]$. Por exemplo, Quinn et al. [38] demonstraram que a hiperacumulação de selénio pelas plantas Stanleya pinnata e Astragalus bisulcatus protegia estas plantas dos tripes-das-flores-ocidentais (Frankliniella occidentalis) e do ácaro aranha (Tetranychus urticae). Estes dois herbivoros preferiam consistentemente alimentar-se de plantas e folhas com menor quantidade de selénio e não foram capazes de proliferar em plantas com uma quantidade muito elevada deste metal. Outro estudo, por Godinho et al. [39], demonstrou que a hiperacumulação de grandes quantidades de cádmio pelo tomateiro (Solanum lycopersicum) diminuía a fecundidade e sobrevivência de duas espécies de ácaros aranha ( $T$. urticae e T. evansi). A hiperacumulação de cádmio também aumentou a resistência a infeções fúngicas pela planta Noccaea praecox [36].

No entanto, a hiperacumulação de metais pelas plantas pode levar a que os herbívoros, por sua vez, se adaptem a altas concentrações de metais [40-42]. Por exemplo, Freeman et al. [43] demonstraram que a traça diamante (Plutella xylostella) tinha uma elevada fecundidade e desenvolvimento em Stanleya pinnata, uma hiperacumuladora de selénio, pelo facto de conseguir acumular selénio sob a forma de metiloselenocisteína (a forma química usada pela planta), diminuindo a toxicidade do selénio. Este estudo é dos poucos que investiga como respondem os herbívoros às plantas hiperacumuladoras [41,44]. $\mathrm{Na}$ verdade, a grande maioria dos estudos não investigam o impacto da adaptação de herbívoros nas interações ecológicas, nem os mecanismos genéticos e fenotípicos (i.e., as características físicas ou químicas dos organismos, por exemplo acumular metais em diferentes tecidos) pelos quais os artrópodes se adaptam à poluição por metais pesados, nem quais as consequências para o ecossistema.

\section{Quais as consequências da acumulação de metais para os ecossistemas?}

A poluição antropogénica aumentou drasticamente no último século $[5,6]$. Os impactos negativos dos poluentes sobre a biodiversidade não se limitam a níveis tróficos específicos, mas afetam a estrutura e o funcionamento das redes alimentares $[6,45]$. Ao contrário de outras espécies químicas, os metais pesados no solo são estáveis e não sofrem praticamente degradação biológica ou química e, por isso, persistem ao longo de muito tempo, mesmo que a fonte de contaminação seja removida $[7,46]$. Isso faz com que seja mais fácil a passagem de metais através das cadeias tróficas (Figura 1). 


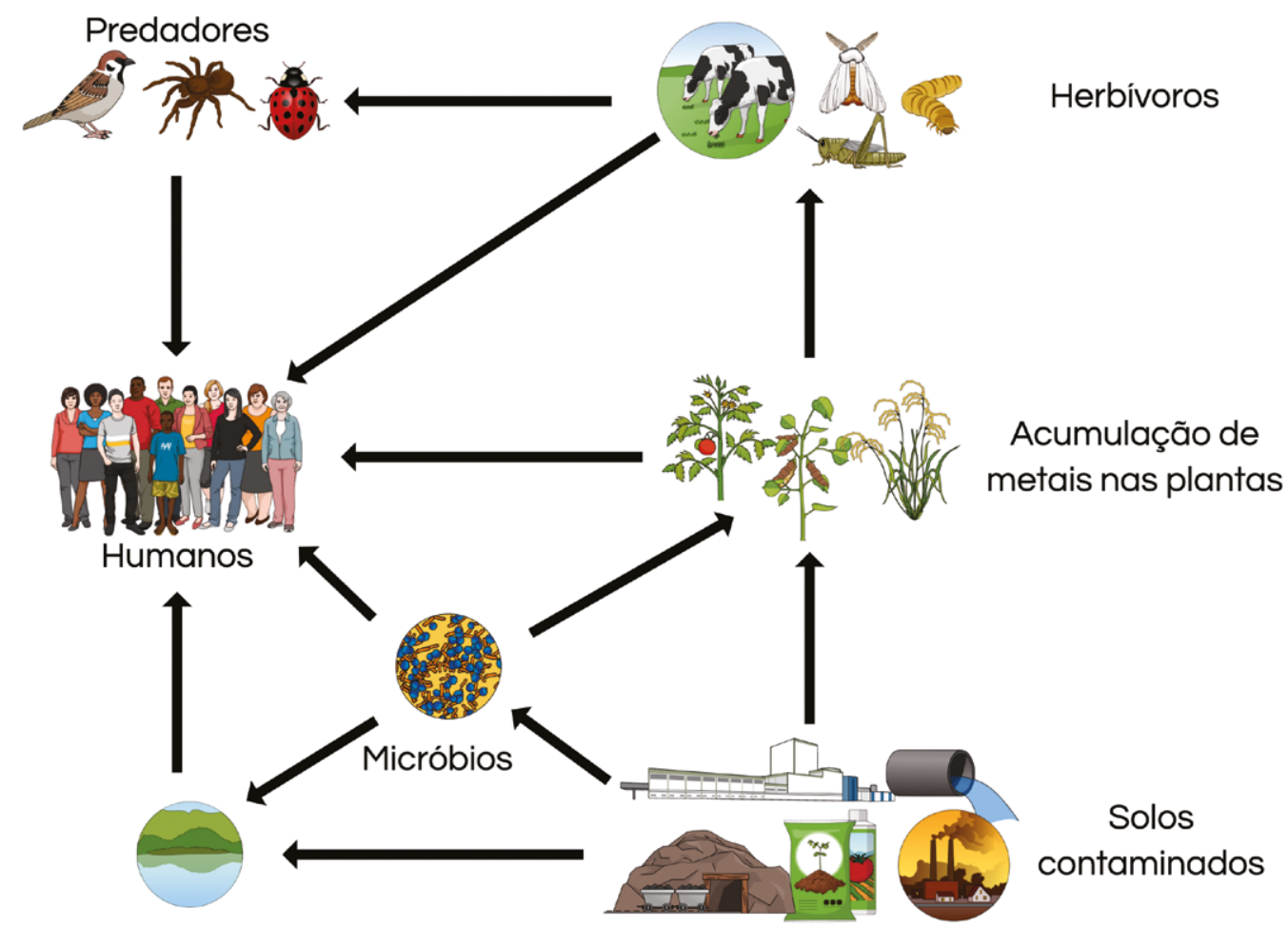

\section{Águas contaminadas}

Figura 1 - Esquema representativo das diferentes vias pelas quais os metais acumulados no solo podem passar para diferentes partes do ecossistema.

As concentrações elevadas de metais pesados podem desestabilizar os processos do solo que são mediados por micróbios, como a decomposição, que fica mais lenta em solos com grandes quantidades de metais pesados [47-49]. Assim, para além do efeito direto nas plantas, a poluição por metais pesados leva também à mudança da composição e diversidade do microbioma (conjunto de microrganismos presentes num determinado local) do solo [47-49] e entre os micróbios e as plantas, já que os microbiomas do solo e das plantas estão altamente interconectados $[50,51]$. Estas alterações podem afetar indiretamente a resposta das plantas a stress biótico e abiótico [50,52,53]. Ainda assim, a ecologia e evolução do microbioma são componentes da resposta dos ecossistemas à poluição por metais pouco exploradas e a maioria dos estudos não investiga quais as consequências das mudanças no microbioma do solo e da planta para a restante rede trófica [51,53].

A transferência e a bioacumulação de metais nos diferentes ecossistemas dependem não só das propriedades dos metais, mas também de como as plantas e animais lidam com a presença de metais e a estrutura da cadeia trófica. Por exemplo, Butt et al. [54] observaram que a acumulação de metais variava não só com a concentração no solo, mas também com o mecanismo de absorção, com o zinco e o cádmio a serem mais acumulados pelas plantas (por partilharem o mesmo tipo de transportador) do que o chumbo. Também verificaram que os gafanhotos acumulavam mais metais que os afídios, muito provavelmente devido ao modo como se alimentam: os afídios (que se alimentam do floema das plantas) absorvem os metais na sua forma iónica, enquanto os gafanhotos (que mastigam a folha) ingerem material foliar onde estão guardados os metais. Curiosamente, observaram que as joaninhas (predadores de afídios) também acumulavam mais metais, sugerindo que a acumulação de metais para o terceiro nível trófico pode ocorrer, mesmo quando existe pouca concentração de metais no segundo nível trófico. Não obstante, um estudo por Naikoo et al. [45] demonstrou que a bioacumulação e transferência do chumbo entre afídios e joaninhas era baixa, sugerindo que a transferência de metais através da cadeia trófica vai depender muito do metal em estudo.

Para além do modo de alimentação, o ambiente onde os organismos vivem também é determinante para prever a quantidade de metais que se pode acumular. Nomeadamente, os isópodes detritívoros que vivem em solos com uma elevada concentração de metais na camada em decomposição e se alimen- 
tam de matéria orgânica contaminada, têm níveis de acumulação de metais muito superior à de, por exemplo, invertebrados do género Coleoptera, que não estão em contacto com essa camada do solo [55]. Enquanto alguns invertebrados apresentam modificações comportamentais para evitar plantas com alto teor de metais pesados $[38,43]$ outros invertebrados tiram partido da presença de metais nas plantas e acumulam-nos como defesa contra predadores [43,56,57], o que pode transportar o metal mais acima na cadeia alimentar $[6,54]$.

A passagem de metais pesados para mamíferos ou aves é feita maioritariamente através de ingestão de animais ou plantas contaminadas, embora possa também ser feita através de absorção pela pele, transferência pela placenta (no caso dos mamíferos), inalação, etc. [6,58]. Similarmente aos invertebrados, a passagem dos metais depende não só da quantidade acumulada na planta, mas também da espécie a ser consumida, do tipo de alimentação, do tipo de metal a ser acumulado, etc. [6]. Por exemplo, nos mamíferos é mais provável ocorrer a excreção do excesso de metais essenciais do que metais não essenciais $[59,60]$. Animais como vacas, ovelhas, cabras e cavalos podem ser frequentemente expostos a plantas contaminadas por metais pesados, uma vez que consomem uma grande quantidade de plantas numa única zona [6]. No entanto, a quantidade de metais consumidos vai depender se as plantas são hiperacumuladoras ou não hiperacumuladoras e do tipo de alimentação dos animais: por exemplo, as vacas e cabras consomem folhas e não raízes, enquanto javalis consomem mais raízes e potencialmente também solo $[61,62]$.

No caso dos humanos, a fonte mais comum de contaminação com metais pesados é através da água e dos alimentos [63,64], ou seja, através de colheitas plantadas em solos contaminados, de animais que se alimentaram de pastos contaminados, ou de predadores que se alimentaram de animais contaminados. Algumas das fontes mais consistentes de contaminação de metais são os fertilizantes à base de fósforo $[7,65,66]$, o uso de pesticidas com metais como compostos ativos [67] ou aplicação de efluentes de esgoto como fertilizantes em campos agrícolas $[64,68,69]$. A ingestão de plantas crescidas nestes campos contaminados pode levar à contaminação dos humanos, principalmente através da ingestão de tubérculos, uma vez que a maior parte das plantas cultivadas não são hiperacumuladoras.

Como os metais são bastante estáveis no solo, a eliminação destes tem de ser feita de forma ativa pelo Homem [7]. Os dois mecanismos atualmente usados para a descontaminação dos solos são técnicas físico-químicas (que são altamente dispendiosas e muitas vezes utilizam compostos difíceis de sintetizar $[7,70]$ ) ou a fitorremediação por plantas (em que as plantas absorvem e acumulam os contaminantes do solo) que depois são colhidas e tratadas em instalações apropriadas [7]. Este último método é uma alternativa mais sustentável e amiga do ambiente, sendo também pouco dispendiosa, embora necessite de tempo para as plantas crescerem. Para esta estratégia ser eficaz é necessário estudar previamente o tipo de contaminação do solo e escolher as plantas que acumulem os metais presentes em maiores concentrações no local. A combinação da fitorremediação com a utilização de adubos ácidos que aumentem a disponibilidade dos metais no solo e facilitem a absorção pelas plantas poderá ser uma estratégia a longo prazo para eliminar os resíduos de metais pesados do solo [6,7].

\section{Agradecimentos}

À Marta Santos e à Catarina Santos por comentários construtivos durante a escrita deste artigo. À FCT (CEECIND/02616/2018) e à L'Òreal Women in Science pelo financiamento.

\section{Nota}

${ }^{1}$ Apesar de haver diversas definições de metais pesados, neste artigo este termo refere-se aos metais e metaloides que são tóxicos para organismos vivos, mesmo quando presentes em baixas quantidades.

\section{Referências}

[1] G. R. Cramer, K. Urano, S. Delrot, M. Pezzotti, K. Shinozaki, BMC Plant Biol. 2011, 11, 1-14. DOI: 10.1186/1471-2229-11-163.

[2] S. L. Kochhar, S. K. Gujral, in Plant Physiology: Theory and Application 2020 545-589.

[3] G. Petschenka, A. A. Agrawal, Curr. Opin. Insect Sci. 2016, 14, 17-24. DOI: 10.1016/j.cois.2015.12.004.

[4] M. Erb, Trends Plant Sci. 2018, 23, 187-194. DOl: 10.1016/j. tplants.2017.11.005.

[5] European Environment Agency, EEA, 2015, European environment - state and outlook 2015: Assessment of global megatrends (Copenhaga, 2015)

[6] J. E. Gall, R. S. Boyd, N. Rajakaruna, Environ. Monit. Assess. 2015, 187, 201. DOI: $10.1007 / \mathrm{s} 10661-015-4436-3$.

[7] S. Ashraf, Q. Ali, Z. A. Zahir, S. Ashraf, H. N. Asghar, Ecotoxicol. Environ. Saf. 2019, 174, 714-727. DOI: 10.1016/j.ecoenv.2019.02.068.

[8] C. Poschenrieder, R. Tolrà, J. Barceló, Trends Plant Sci. 2006, 11, 288-295. DOI: 10.1016/j.tplants.2006.04.007.

[9] N. Rascio, F. Navari-Izzo, Plant Sci. 2011, 180, 169-181. DOI: 10.1016/j. plantsci.2010.08.016.

[10] D. J. Ballhorn, S. Kautz, M. Heil, A. D. Hegeman, Plant Signal. Behav. 2009, 4, 743-745. DOI: 10.4161/psb.4.8.9088.

[11] R. L. Woodman, G. W. Fernandes, Oikos 1991, 60, 11-19. DOI: $10.2307 / 3544986$. 
[12] P. W. Lucas, I. M. Turner, N. J. Dominy, N. Yamashita, Ann. Bot. 2000, 86, 913-920. DOl: 10.1006/anbo.2000.1261.

[13] J. X. Becerra, Am. Zool. 2001, 41, 865-876. D0I: 10.1093/icb/41.4.865.

[14] D. A. Levin, Annu. Rev. Ecol. Syst. 1976, 7, 121-159. DOl: 10.1146/annurev. es.07.110176.001005.

[15] I. Kaplan, R. Halitschke, A. Kessler, S. Sardanelli, R. F. Denno, Ecology 2008, 89, 392-406. DOI: 10.1890/07-0471.1.

[16] M. G. Bidart-Bouzat, J. Integr. Plant Biol. 2008, 50, 1339-1354. DOI: 10.1111/j.1744-7909.2008.00751.x

[17] A. Mithöfer, W. Boland, Annu. Rev. Plant Biol. 2012, 63, 431-450. DO 10.1146/annurev-arplant-042110-103854

[18] I. Kaplan, PLoS Biol. 2012, 10, e1001437. DOI: 10.1371/journal.pbio.1001437.

[19] A. Katsanis, S. Rasmann, K. A. Mooney, PLoS One 2016, 11, 1-17. DOI: 10.1371/ journal.pone. 0155716

[20] A. C. Hörger, H. N. Fones, G. M. Preston, Front. Plant Sci. 2013, 4, 1-11. DOl: 10.3389/fpls.2013.00395.

[21] R. S. Boyd, New Phytol. 2004, 162, 563-567. DOI: 10.1111/j.14698137.2004.01079.x.

[22] P. Zornoza, S. Vázquez, E. Esteban, M. Fernández-Pascual, R. Carpena, Plant Physiol. Biochem. 2002, 40, 1003-1009. DOI: 10.1016/S09819428(02)01464-X

[23] T. Watanabe, M. Osaki, Commun. Soil Sci. Plant Anal. 2006, 33, 1247-1260. DOI: $10.1081 /$ CSS -120003885

[24] N. Rascio, F. D. Vecchia, N. La Rocca, R. Barbato, C. Pagliano, M. Raviolo, C. Gonnelli, R. Gabbrielli, Environ. Exp. Bot. 2008, 62, 267-278. DOI: 10.1016/j. envexpbot.2007.09.002

[25] J. L. Hall, J. Exp. Bot. 2002, 53, 1-11. DOI: 10.1093/jxb/53.366.1.

[26] G.R. Rout, J. Panigrahi, Analysis of Signaling Pathways During Heavy Metal Toxicity: A Functional Genomics Perspective, in Elucidation of Abiotic Stress Signaling in Plants, G. K. Pandey (Ed), Springer, Nova lorque, 2015, 295-322. DOI: 10.1007/978-1-4939-2540-7.

[27] U. Krämer, Annu. Rev. Plant Biol. 2010, 61, 517-534. DOI: 10.1146/annurevarplant-042809-112156.

[28] E. M. Jhee, R. S. Boyd, M. D. Eubanks, New Phytol. 2005, 168, 331-344. DOl: 10.1111/j.1469-8137.2005.01504.x.

[29] R. Kastori, M. Petrović, N. Petrović, J. Plant Nutr. 1992, 15, 2427-2439. DOI: 10.1080/01904169209364485

[30] P. Das, S. Samantaray, G. R. Rout, Environ. Pollut. 1997, 98, 29-36. DOl: 10.1016/S0269-7491(97)00110-3.

[31] B. D. Jaffe, M. E. Ketterer, S. M. Shuster, J. Plant Ecol. 2018, 11, 553-559. DOl: 10.1093/jpe/rtx020.

[32] A. Manara, E. Fasani, A. Furini, G. DalCorso, Plant Cell Environ. 2020, 43, 2969-2986. DOI: 10.1111/pce.13821.

[33] R. S. Boyd, Plant Sci. 2012, 195, 88-95. DOI: 10.1016/j.plantsci.2012.06.012

[34] R. S. Boyd, S. N. Martens, Chemoecology 1998, 8, 1-7. DOI: 10.1007/ s000490050002

[35] A. Mohiley, K. Tielbörger, M. Seifan, M. Gruntman, Funct. Ecol. 2020, 34 658-668. DOI: 10.1111/1365-2435.13502.

[36] M. Llugany, S. R. Martin, J. Barceló, C. Poschenrieder, Plant Cell Rep. 2013, 32, 1243-1249. DOI: 10.1007/s00299-013-1427-0.

[37] S. P. Ribeiro, V. Londe, A. P. Bueno, J. S. Barbosa, T. L. Corrêa, T. Soeltl, M. Maia, V. D. Pinto, G. de F. Dueli, H. C. de Sousa, A. R. Kozovits, H. A. Nalini, Plant Species Biol. 2017, 32, 147-155. DOI: 10.1111/1442-1984.12136.

[38] C. F. Quinn, J. L. Freeman, R. J. B. Reynolds, J. J. Cappa, S. C. Fakra, M. A. Marcus, S. D. Lindblom, E. K. Quinn, L. E. Bennett, E. A. H. Pilon-Smits, BMC Ecol. 2010, 10, 19. DOI: 10.1186/1472-6785-10-19.

[39] D. P. Godinho, H. C. Serrano, A. Bernardes, D. Silva, C. Branquinho, S. Magalhães, R. S. Boyd, Front. Plant Sci. 2018, 9, 1723. DOl: 10.3389/ fpls.2018.01723.

[40] A. Loria, M. E. Cristescu, A. Gonzalez, Evol. Appl. 2019, 12, 1259-1273. DOI: 10.1111/eva.12782

[41] T. K. S. Janssens, D. Roelofs, N. M. Van Straalen, Insect Sci. 2009, 16, 3-18. DOI: 10.1111/j.1744-7917.2009.00249.x.

[42] C. Baumann, A. Beil, S. Jurt, M. Niederwanger, O. Palacios, M. Capdevila, S. Atrian, R. Dallinger, O. Zerbe, Angew. Chemie Int. Ed. 2017, 56, 4617-4622. DOI: 10.1002/anie.201611873.
[43] J. L. Freeman, C. F. Ouinn, M. A. Marcus, S. Fakra, E. A. H. Pilon-Smits, Curr. Biol. 2006, 16, 2181-2192. DOI: 10.1016/j.cub.2006.09.015

[44] T. J. S. Merritt, A. J. Bewick, Front. Genet. 2017, 8, 1-6. DOI: 10.3389/ fgene.2017.00172

[45] M. I. Naikoo, M. I. Dar, F. A. Khan, F. Raghib, N. Rajakaruna, Environ. Sci. Pollut. Res. 2019, 26, 23460-23470. DOl: 10.1007/s11356-019-05624-x.

[46] J. Babin-Fenske, M. Anand, Restor. Ecol. 2010, 18, 73-84. DOI: 10.1111/j.1526100X.2010.00665.x

[47] Y. Xie, J. Fan, W. Zhu, E. Amombo, Y. Lou, L. Chen, J. Fu, Front. Plant Sci. 2016, 7, 1-12. DOI: 10.3389/fpls.2016.00755.

[48] Y. P. Chen, Q. Liu, Y. J. Liu, F. A. Jia, X. H. He, Sci. Rep. 2014, 4, 4-9. DOl: $10.1038 /$ srep04287.

[49] X. Li, D. Meng, J. Li, H. Yin, H. Liu, X. Liu, C. Cheng, Y. Xiao, Z. Liu, M. Yan, Environ. Pollut 2017 231, 908-917. D0l: 10.1016/j.envpol.2017.08.057.

[50] C. R. Fitzpatrick, Z. Mustafa, J. Viliunas, J. Evol. Biol. 2019, 32, 438-450. DOI: 10.1111/jeb.13426.

[51] B. Koskella, L. J. Hall, C. J. E. Metcalf, Nat. Ecol. Evol. 2017, 1, 1606-1615. DOI: 10.1038/s41559-017-0340-2.

[52] C. J. Hubbard, B. Li, R. McMinn, M. T. Brock, L. Maignien, B. E. Ewers, D. Kliebenstein, C. Weinig, Mol. Ecol. 2019, 28, 1801-1811. DOI: 10.1111/ mec.14989.

[53] B. Koskella, J. Bergelson, Phil. Trans. R. Soc. B 2020, 375, 20190604. DOI 10.1098/rstb.2019.0604

[54] A. Butt, Ourat-ul-Ain, K. Rehman, M. X. Khan, T. Hesselberg, Environ. Monit. Assess. 2018, 190, 698. DOl: 10.1007/s10661-018-7051-2

[55] A. Heikens, W. J. G. M. Peijnenburg, A. J. Hendriks, Environ. Pollut. 2001, 113 385-393. DOI: 10.1016/S0269-7491(00)00179-2.

[56] R. S. Boyd, M. A. Wall, T. Jaffré, Insect Sci. 2006, 13, 271-277. DOI: 10.1111/j.1744-7917.2006.00094.x.

[57] R. S. Boyd, Am. Midl. Nat. 2009, 146, 186-198. DOI: 10.1674/0003$0031(2001) 146$.

[58] N. van den Brink, D. Lammertsma, W. Dimmers, M. C. Boerwinkel, A. van der Hout, Environ. Pollut. 2010, 158, 245-251. D0I: 10.1016/j. envpol.2009.07.013.

[59] K. Veltman, M. A. J. Huijbregts, T. Hamers, S. Wijnhoven, A. J. Hendriks, Environ. Toxicol. Chem. 2007, 26, 1488-1496. DOI: 10.1897/06-518R.1.

[60] A. Kabata-Pendias, H. Pendias, Br. Med. J. 1949, 2, 1355. DOI: 10.1136/ bmj.2.4640.1355-a.

[61] M. M. Reglero, L. Monsalve-González, M. A. Taggart, R. Mateo, Sci. Tota Environ. 2008, 406, 287-297. DOl: 10.1016/j.scitotenv.2008.06.001.

[62] M. M. Reglero, M. A. Taggart, L. Monsalve-González, R. Mateo, Environ. Pollut. 2009, 157, 1388-1395. DOl: 10.1016/j.envpol.2008.11.036.

[63] P. Zhuang, M. B. McBride, H. Xia, N. Li, Z. Li, Sci. Total Environ. 2009, 407, 1551-1561. DOI: 10.1016/j.scitotenv.2008.10.061

[64] Q. Cai, M. L. Long, M. Zhu, Q. Z. Zhou, L. Zhang, J. Liu, Environ. Pollut. 2009 157, 3078-3082. DOI: 10.1016/j.envpol.2009.05.048

[65] Z. Atafar, A. Mesdaghinia, J. Nouri, M. Homaee, M. Yunesian, M. Ahmadimoghaddam, A. H. Mahvi, Environ. Monit. Assess. 2010, 160, 83-89. DOI: 10.1007/s10661-008-0659-x.

[66] W. Jiao, W. Chen, A. C. Chang, A. L. Page, Environ. Pollut. 2012, 168, 44-53. DOI: 10.1016/i.envpol.2012.03.052.

[67] P. Schlegel, S. Durosoy, A. W. Jongbloed, Trace elements in animal production systems (Wageningen Academic Publishers, Países Baixos), 2008. DOI: 10.3920/978-90-8686-638-0.

[68] F. A. Nicholson, S. R. Smith, B. J. Alloway, C. Carlton-Smith, B. J. Chambers, Sci. Total Environ. 2003, 311, 205-219. D0I: 10.1016/S00489697(03)00139-6.

[69] M. Muchuweti, J. W. Birkett, E. Chinyanga, R. Zvauya, M. D. Scrimshaw, J. N. Lester, Agric. Ecosyst. Environ. 2006, 112, 41-48. DOI: 10.1016/j. agee.2005.04.028

[70] S. Xia, Z. Song. P. Jeyakumar, S. M. Shaheen, J. Rinklebe, Y. S. Ok, N. Bolan, H. Wang, Crit. Rev. Environ. Sci. Technol. 2019, 49, 1027-1078. DOI: 10.1080/10643389.2018.1564526.

\section{Inês Fragata}

Centro de Ecologia, Evolução e Alterações Ambientais e da Faculdade de Ciências da Universidade de Lisboa. É Investigadora Júnior do Centro de Ecologia, Evolução e Alterações Ambientais e da Faculdade de Ciências da
Universidade de Lisboa. Estuda como é que a evolução da competição entre herbívoros é afetada por fatores abióticos e bióticos, ao nível genómico e fenotípico. irfragata@fc.ul.pt ORCID.org/0000-0001-6865-1510 